\title{
ОПИТУВАЛЬНИКИ ЯК ОСНОВНІ ІНСТРУМЕНТИ В ДІАГНОСТИЦІ РОЗЛАДІВ СНУ
}

\section{Опитувальники як основні інструменти в діагностиці розладів сну}

\section{Л. П. Мазур, М. І. Марущак, О. В. Батюх}

Тернопільський національний медичний університет імені І. Я. Горбачевського МОЗ України

Резюме. Понад 6 \% дорослого населення у високорозвинених країнах потерпає від хронічного безсоння, а поширеність його у різних країнах Європи суттєво різниться і становить від 5,7 до $19 \%$. За даними поширення безсоння в Канаді, майже у 70 \% пацієнтів протягом року спостерігається тривале збереження його симптомів.

Мета дослідження - проаналізувати наявні опитувальники для діагностики безсоння і визначити оптимальні інструменти для оцінки розладів сну, їх вираження та характеристик.

Матеріали і методи. Опрацьовано наукові публікації за останнє десятиліття з використанням ресурсів мережі «lнтернет», вітчизняних фрахових видань, медичної бази даних MEDLINE/PubMed. Ключовими словами для пошуку були: «безсоння», «опитувальник».

Результати. Зәідно з Європейськими настановами щодо діагностики та лікування безсоння, рекомендованими для діагностики наявності інсомнії та оцінки їі тяжкості є ряд опитувальників, зокрема Пітсбурзький індекс якості сну (PSQI), індекс тяжкості безсоння (ISI), Бергенська шкала безсоння (BSAS) та індикатор стану сну. На запитання усіх рекомендованих анкет пацієнт відповідає самостійно, тривалість кожного сеансу становить 5-10 хв. Застосування поєднання цих інструментів дозволяє виявити порушення сну, дослідити його частоту, тривалість, характеристики та впив на фрункціонування особи.

Висновки. Застосування опитувальників у дослідженнях із діагностики безсоння $\epsilon$ ефективним та обірунтованим, а поєднання декількох анкет є оптимальним методом для оцінки розладів сну, їх вираження та характеристик.

Ключові слова: безсоння; розлади сну; опитувальники.

\section{ВСТУП}

Понад 6 \% дорослого населення у високорозвинених країнах потерпає від хронічного безсоння, при цьому більше страждають від інсомнії чоловіки

\section{Questionnaires as the key tools for diagnosing sleep} disorders

L. P. Mazur, M. I. Marushchak, O. V. Batiukh

I. Horbachevsky Ternopil National Medical University

e-mail: mazur@tdmu.edu.ua

Summary. More than $6 \%$ of adults in highly developed countries suffer from chronic insomnia, and its prevalence in different European countries varies significantly from 5.7 to $19 \%$. According to the prevalence of insomnia in Canada, almost $70 \%$ of patients have a long-term persistence of its symptoms during the year.

The aim of the study - to analyze the available questionnaires for the diagnosis of insomnia and to determine the optimal tools for assessing sleep disorders, their severity and characteristics.

Materials and Methods. Scientific publications for the last decade have been processed using Internet resources, domestic publications, and the MEDLINE/PubMed medical database. The key words for the search were "insomnia", "questionnaire".

Results. According to the European Guidelines for the Diagnosis and Treatment of Insomnia, a number of questionnaires are recommended for diagnosing insomnia and assessing its severity, including the Pittsburgh Sleep Quality Index (PSQI), the Insomnia Severity Index (ISI), the Bergen Insomnia Scale (BSAS) and the Sleep Status Indicator. Patients answer the questions of all recommended questionnaires independently, the duration of each session is 5-10 minutes. The use of a combination of these tools allows detecting sleep disorders, to estimate its frequency, duration, characteristics and impact on the person functioning.

Conclusions. The use of questionnaires in research for diagnosing insomnia is effective and reasonable, and a combination of several questionnaires is the optimal method for assessing sleep disorders, their severity and characteristics.

Key words: insomnia; sleep disorders; questionnaires.

і особи старшого віку (Ohayon, 2002; Zhang and Wing, 2006). За останніми даними, серед жителів Норвегії, Великобританії та Німеччини простежується зростання поширення безсоння у загальній 
популяції до 10 \% (Calem et al., 2012; Marschall et al., 2017; Pallesen et al., 2014). Поширеність безсоння у різних країнах Європи суттєво різниться і становить від 5,7 \% у Німеччині до 19 \% - у Франції. За даними поширеності безсоння в Канаді, майже у 70 \% пацієнтів протягом року спостерігається тривале збереження його симптомів (Morin et al., 2009). Поширення приймання гіпнотиків широко варіює в різних європейських країнах. Зокрема, протягом 10-річного періоду в Норвегії рівень приймання гіпнотиків підвищився з 7 до 11 \% (Pallesen et al., 2001, 2004) [1].

Метою дослідження було проаналізувати наявні опитувальники для діагностики безсоння і визначити оптимальні інструменти для оцінки розладів сну, їх вираження та характеристик.

\section{МАТЕРІАЛИ І МЕТОДИ}

Опрацьовано наукові публікації за останнє десятиліття з використанням ресурсів мережі «Інтернет», вітчизняних фрахових видань, медичної бази даних MEDLINE/PubMed. Ключовими словами для пошуку були: «безсоння», «опитувальник».

\section{РЕЗУЛЬТАТИ Й ОБГОВОРЕННЯ}

Поточну редакцію європейських настанов з діагностики та лікування безсоння розробила робоча група Європейського товариства з вивчення сну (ESRS, 2017). Згідно з цими настановами, рекомендованими для діагностики наявності інсомнії та оцінки її тяжкості, є ряд опитувальників. Для суб'єктивної оцінки якості сну за попередній місяць доцільно застосовувати Пітсбурзький індекс якості cну (PSQI), проте оскільки PSQI не є діагностичною шкалою, то рекомендовано поєднувати його використання з іншими інструментами. Достатньо надійним і чутливим у діагностиці ступеня тяжкості безсоння є індекс тяжкості безсоння (ISI), також перспективними з огляду психометричних показників зазначені Бергенська шкала безсоння (BSAS) та індикатор стану сну (ICC) [1].

Оскільки психічні розлади часто асоціюються з порушеннями сну, то PSQI було розроблено для оцінки загальної якості сну саме в цій популяції. На запитання анкети пацієнт відповідає самостійно. Кожне з 19 запитань опитувальника поділене в одну із семи підкатегорій: суб'єктивна якість сну, прихована сонливість, тривалість сну, звичайна еорективність сну, розлади сну, споживання снодійних препаратів, а також денна дисорункція. Також анкета містить п'ять додаткових запитань, на які необхідно відповідати партнеру або співмешканцю респондента, що включені 3 клінічною метою та відповіді на які не включаються в загальний бал. Загальна тривалість сеансу анкетування триває 510 хв. Розробники інструмента провели апробацію опитувальника PSQI у популяції віком 24-83 роки. Валідність анкети доведена шляхом здійснення тестувань у різних популяціях, зокрема серед пацієнтів із великим депресивним розладом, розладами початку і підтримання сну, надмірною сонливістю, раком та фріброміалгією. Анкета складається із комбінації запитань лайкертівського та відкритого типів. Респондентам запропоновано вказати, як часто вони відчували певні труднощі зі сном за останній місяць і оцінити в загальному якість їх сну. Оцінка за кожне запитання коливається від 0 до 3, при цьому вищі бали вказують на більш виражені порушення сну. Розробники вказують граничний бал для анкети за шкалою загальної оцінки як 5, як це визначено у 88,5 \% респондентів дослідної групи під час проведення їх валідаційного дослідження. При проведенні ініціального дослідження 3 апробації опитувальника PSQI за шкалою загальної оцінки встановлено надійність за внутрішнім узгодженням $\alpha=0,83$, ретестову надійність - 0,85, чутливість 89,6 \%, а специфрічність - 86,5\% [2].

Дослідження із застосуванням інструмента PSQI та його модифрікованих версій протягом останніх років провели ряд науковців. N. M. Farah, T. Saw Yee, H. F. Mohd Rasdi (2019) застосували редакцію опитувальника для Малайзії при обстеженні дорослих жителів країни [3]. Y. Huang, M. Zhu (2020) довели асоціацію підвищеного індексу за опитувальником із зростанням частоти депресії у дорослих жителів США [4]. H. Purani, S. Friedrichsen, A. M. Allen et al. (2019) використали інструмент PSQI при вивченні стану сну в курців [5]. B. Krishnan, R. K. Sanjeev, R. G. Latti (2020) за допомогою анкети вивчали якість сну в студентів-медиків, які користувалися смарторонами в нічний час [6].

Опитувальник показника тяжкості інсомнії (ISI) розроблено як короткий інструмент для перевірки характеристик безсоння. Анкета складається із семи пунктів, у яких респондентам запропоновано оцінити характер та симптоми їх порушень сну за допомогою шкали лайкертівського типу. Запитання стосуються суб'єктивних якостей сну респондента, включаючи тяжкість симптомів, задоволення своїм режимом сну, ступінь вираження інсомнії, наскільки це впливає на щоденне функціонування, наскільки безсоння впливає на оточуючих та загальний рівень дистресу, спричинений розладами сну. Відповіді на кожне із запитань можна оцінити за шкалою від 0 до 4 балів, де більша кількість балів визначає більш виражені розлади сну. Загальна тривалість сеансу анкетування станосить не більше 5 хв, респондент відповідає на запитання самостійно. Автори провели апробацію анкети у двох окремих популяціях людей із безсонням віком 17-84 роки. Хоча автори вказують, що обрана ними система порогових балів загальної оцінки не $є$ валідованою, проте ми запропонували залежно від кількості набраних 
балів оцінювати результат від «немає клінічно значимого безсоння» до «сильне клінічне безсоння». При проведенні ініціального дослідження з апробації опитувальника ISI за шкалою загальної оцінки встановлено надійність за внутрішнім узгодженням $\alpha=0,74$ та кореляцію між елементами і загальною оцінкою від 0,36 до 0,54 [2].

Протягом останнього часу дану шкалу було використано в ряді досліджень у пацієнтів із СОVID-19. M. G. Mazza, R. De Lorenzo, C. Conte et al. (2020) застосували ISI при вивченні вираження інсомнії у постковідних пацієнтів із тривожністю та депресією [7]. L. Shi, Z. A. Lu, J. Y. Que et al. (2020) за допомогою даного опитувальника проводили дослідження серед дорослого населення в Китаї під час пандемії [8]. Порівняння між ступенем тяжкості інсомнії за Афрінською шкалою безсоння та ISI здійснили I. Okajima, T. Miyamoto, A. Ubara (2020) [9]. D. M. Wallace, W. K. Wohlgemuth (2019) вивчали профрілі фракторів ризику тяжкості безсоння у ветеранів із синдромом нічного апное в США [10].

Бергенська шкала безсоння (BSAS) побудована на основі сучасних фрормальних і клінічних діагностичних критеріїв безсоння. Шкала складається із шести пунктів, з яких перші три стосуються настання сну, утримання сну та раннього безсоння. Відповідаючи на наступні три запитання, респондент вказує, чи відчуває себе достатньо відпочилим після сну, чи наявні порушення вдень і чи є незадоволення поточним сном. Ця шкала була апробована у трьох окремих популяціях: 320 студентів, 2645 дорослого населення та 225 пацієнтів. Надійність за внутрішнім узгодженням у трьох популяціях становила 0,79; 0,87 та 0,80 відповідно. Двотижнева ретестова надійність для студентів становила 0,77. За усіма показниками зроблено висновок, що Бергенська шкала безсоння має хороші психометричні властивості. Опитувальник BSAS є одним із небагатьох інструментів для вивчення інсомнії, який надає нормативні дані для порівняння і який був перевірений на основі суб'єктивних, а також полісомнографрічних даних [11].

Опитувальник BSAS використали G. D'Ettorre, V. Pellicani, A. Caroli, M. Greco (2020) для оцінки розладів сну в медсестер, які працюють позмінно
[12]. A. J. Lundervold, D. A. Jensen, J. Haavik (2020) вивчали розлади сну в дорослих осіб з алкогольною залежністю [13]. I. S. Olufsen, M. E. Sørensen, B. Bjorvatn (2020) проводили дослідження серед пацієнтів із порушеннями сну, тривожністю та депресією [14]. Опитувальник BSAS застосовували при проведенні ряду багатоцентрових рандомізованих досліджень розладів сну, зокрема у вагітних жінок для визначення фракторів ризику післяпологових психічних порушень [15].

Анкета «Індикатор стану сну» $€$ досить новим інструментом для оцінки порушень сну, що на відміну від більшості інших анкет для оцінки безсоння основаних на чинних критеріях DSM-5 для розладів сну. Складається із 8 запитань, на які пацієнт відповідає самостійно. В запитаннях оцінюються розлади при засипанні, підтримання сну, якість сну, фрункціонування респондента в денний час, денна продуктивність, тривалість наявності проблем зі сном, кількість ночей на тиждень, коли виникали проблеми зі сном, а також ступінь вираження порушень сну. Загальна оцінка за ICC може становити від 0 до 10 балів, при цьому чим вищий бал, тим кращою є якість сну в респондента. В ініціальному дослідженні опитувальників автори зіставили результати за ICC із результатами анкетування за інструментами PSQI та ISI, при цьому надійність за внутрішнім узгодженням становила 0,86 [16].

Опитувальник ICC та його версії апробувалися та застосовувалися у ряді багатоцентрових рандомізованих досліджень як для діагностики характеру розладів сну, так і для оцінки ефективності методів терапії [17-19].

Для оптимальної діагностики наявності розладів сну, а також характеристик за ступенем тяжкості безсоння у дослідженнях переважно застосовують декілька опитувальників [20].

\section{ВИСНОВКИ}

Використання опитувальників у дослідженнях із діагностики безсоння $є$ еорективним та обґрунтованим, а поєднання декількох анкет є оптимальним методом для оцінки розладів сну, їх вираження та характеристик.
СПИСОК ЛІТЕРАТУРИ

1. Riemann D. European guideline for the diagnosis and treatment of insomnia / D. Riemann, C. Baglioni, C. Bassetts // J. Sleep Res. - 2017. - Vol. 26. - P. 675-700.

2. Shahid A. STOP, THAT and one hundred other sleep scales / A. Shahid, K. Wilkinson, S. Marcu, C.M. Shapiro // Springer New York Dordrecht Heidelberg London. - 421 p.

3. Farah N. M. Self-reported sleep quality using the
Malay version of the Pittsburgh sleep quality index (PSQI-M) in Malaysian adults / N. M. Farah // Int. J. Environ. Res. Public Health. - 2019. - Vol. 16 (23). - P. 4750.

4. Huang Y. Increased Global PSQI Score is associated with depressive symptoms in an adult population from the United States / Y. Huang, M. Zhu // Nat. Sci. Sleep. - 2020. - 12. - P. 487-495. 
5. Purani H. Sleep quality in cigarette smokers: Associations with smoking-related outcomes and exercise / H. Purani, S. Friedrichsen, A. M. Allen // Addict. Behav. 2019. - Vol. 90. - P. 71-76.

6. Krishnan B. Quality of sleep among bedtime smartphone users / B. Krishnan, R. K. Sanjeev, R. G. Latti // Int. J. Prev. Med. - 2020. - Vol. 11. - P. 114.

7. Mazza M. G. Anxiety and depression in COVID-19 survivors: Role of inflammatory and clinical predictors / M. G. Mazza, R. De Lorenzo, C. Conte // Behav. Immun. 2020. - Vol. 89. - P. 594-600.

8. Shi L. Prevalence of and risk factors associated with mental health symptoms among the general population in China during the Coronavirus disease 2019 pandemic I L. Shi, Z. A. Lu, J. Y. Que // JAMA Netw. Open. - 2020. Vol. 3 (7). - P. e2014053.

9. Okajima I. Evaluation of severity levels of the Athens Insomnia Scale based on the criterion of insomnia severity index / I. Okajima, T. Miyamoto, A. Ubara // Int. J. Environ. Res. Public Health. - 2020. - Vol. 17 (23). - P. 8789.

10. Wallace D. M. Predictors of Insomnia Severity Index profiles in United States veterans with obstructive sleep apnea / D. M. Wallace, W. K. Wohlgemuth // J. Clin. Sleep Med. - 2019. - Vol. 15 (12). - P. 1827-1837.

11. Pallesen S. A new scale for measuring insomnia: the Bergen Insomnia Scale / S. Pallesen, B. Bjorvatn, I. H. Nordhus // Percept. Mot. Skills. - 2008. - Vol. 107 (3). - P. 691-706.

12. Shift work sleep disorder and job stress in shift nurses: implications for preventive interventions / G. D'Ettorre, V. Pellicani, A. Caroli, M. Greco // Med. Lav. 2020. - Vol. 111 (3). - P. 195-202.

13. Lundervold A. J. Insomnia, alcohol consumption and

\section{REFERENCES}

1. Riemann D, Baglioni C, Bassetts C. European guideline for the diagnosis and treatment of insomnia. Journal of Sleep Research. 2017;26: 675-700.

2. Shahid A, Wilkinson K, Marcu S, Shapiro CM. STOP, THAT and one hundred other sleep scales. Springer New York Dordrecht Heidelberg London; 2012.

3. Farah NM. Self-Reported Sleep quality using the Malay version of the Pittsburgh Sleep Quality Index (PSQI-M) In Malaysian Adults. International Journal of Environmental Research and Public Health. 2019;16(23): 4750.

4. Huang $Y$, Zhu M. Increased global PSQI score is associated with depressive symptoms in an adult population from the United States. Nature and Science of Sleep. 2020;12: 487-95.

5. Purani H, Friedrichsen S, Allen A.M. Sleep quality in cigarette smokers: Associations with smoking-related outcomes and exercise. Addictive Behaviors. 2019; 90: 71-6.

6. Krishnan B, Sanjeev RK., Latti RG. Quality of sleep among bedtime smartphone users. International Journal of Preventive Medicine. 2020;11: 114.

7. Mazza M.G., De Lorenzo R., Conte C. Anxiety and depression in COVID-19 survivors: Role of inflammatory
ADHD symptoms in adults / A. J. Lundervold, D. A. Jensen, J. Haavik // Front Psychol. - 2020. - Vol. 11. - 1150.

14. Olufsen I. S. New diagnostic criteria for insomnia and the association between insomnia, anxiety and depression / I. S. Olufsen, M. E. Sørensen, B. Bjorvatn // Tidsskr. Nor. Laegeforen. - 2020. - Vol. 140 (1).

15. Osnes R. S. Mid-pregnancy insomnia is associated with concurrent and postpartum maternal anxiety and obsessive-compulsive symptoms: A prospective cohort study / R. S. Osnes, M. Eberhard-Gran, T. Follestad // J. Affect. Disord. - 2020. - Vol. 266. - P. 319-326.

16. Espie C. A. The sleep condition indicator: A clinical screening tool to evaluate insomnia disorder / C. A. Espie, S. D. Kyle, P. Hames // BMJ Open. - 2014. - Vol. 4 (3). e004183.

17. Espie C. A. A randomized, placebo-controlled trial of online cognitive behavioral therapy for chronic insomnia disorder delivered via an automated media-rich web application / C. A. Espie, S. D. Kyle, C. Williams // Sleep. 2012. - Vol. 35 (6). - P. 769-781.

18. Wong M. L. Psychometric properties of the Sleep Condition Indicator and Insomnia Severity Index in the evaluation of insomnia disorder / M. L. Wong, K. N. T. Lau, C. A. Espie // Sleep Med. - 2017. - Vol. 33. - P. 76-81.

19. Bayard S. Validation of a French version of the Sleep Condition Indicator: A clinical screening tool for insomnia disorder according to DSM-5 criteria / S. Bayard, C. Lebrun, K. H. Maudarbocus // J. Sleep Res. - 2017. - Vol. 26 (6). P. 702-708.

20. Сухолєнцев О. М. Експериментальне дослідження порушень сну у пожежних-рятувальників міста Кропивницького й області / О. М. Сухолєнцев, Н. Д. Ковальчук // Вісник Вінницького національного медичного університету. - 2019. - 23, № 3. - С. 504-508.

and clinical predictors. Brain, Behavior and Immunity. 2020;89: 594-600.

8. Shi L, Lu ZA, Que JY. Prevalence of and risk factors associated with mental health symptoms among the general population in China during the Coronavirus disease 2019 pandemic. JAMA Network Open. 2020;3(7): e2014053.

9. Okajima I, Miyamoto T, Ubara A. Evaluation of severity levels of the Athens Insomnia Scale based on the criterion of insomnia severity index. International Journal of Environmental Research and Public Health. 2020;17(23): 8789.

10. Wallace DM, Wohlgemuth WK. Predictors of insomnia severity index profiles in United States veterans with obstructive sleep apnea. Journal of Clinical Sleep Medicine. 2019;15(12): 1827-37.

11. Pallesen S, Bjorvatn B, Nordhus I. H.A new scale for measuring insomnia: the Bergen Insomnia Scale. Perceptual and Motor Skills. 2008;107(3): 691-706.

12. D'Ettorre G, Pellicani V, Caroli A, Greco M. Shift work sleep disorder and job stress in shift nurses: implications for preventive interventions. 2020;111(3): 195-202.

13. Lundervold AJ, Jensen DA, Haavik J. Insomnia,
ISSN 2706-6282(print)

ISSN 2706-6290(online) 
alcohol consumption and ADHD symptoms in adults. Frontiers in Psychology. 2020;11: 1150.

14. Olufsen IS, Sørensen ME, Bjorvatn B. New diagnostic criteria for insomnia and the association between insomnia, anxiety and depression. Tidsskr Nor Legeforen. 2020;140(1).

15. Osnes RS, Eberhard-Gran M, Follestad T. Midpregnancy insomnia is associated with concurrent and postpartum maternal anxiety and obsessive-compulsive symptoms: A prospective cohort study. Journal of Affective Disorders. 2020;266: 319-26.

16. Espie CA, Kyle SD, Hames P. The Sleep Condition Indicator: a clinical screening tool to evaluate insomnia disorder. British Medical Journal Open. 2014;4(3): e004183.

17. Espie C.A, Kyle SD, Williams C. A randomized, placebo-controlled trial of online cognitive behavioral therapy for chronic insomnia disorder delivered via an automated media-rich web application. Sleep. 2012;35(6): 769-81.

18. Wong ML, Lau KNT, Espie CA. Psychometric properties of the Sleep Condition Indicator and Insomnia Severity Index in the evaluation of insomnia disorder. Sleep Medicine. 2017;33: 76-81.

19. Bayard S, Lebrun C, Maudarbocus KH. Validation of a French version of the Sleep Condition Indicator: a clinical screening tool for insomnia disorder according to DSM-5 criteria. Journal of Sleep Research. 2017;26(6): 702-8.

20. Sukholientsev OM, Kovalchuk ND. [Experimental study of sleep disorders in firefighters of the city of Kropyvnytskyi and the region]. Visn Vinntyts nats univer. 2019;23,3: 504-8. Ukrainian. 